\title{
Brain Correlates of Performance in a Free/Cued Recall Task With Semantic Encoding in Alzheimer Disease
}

\author{
$* \dagger \ddagger$ Françoise Lekeu, $\ddagger \S$ Martial Van der Linden, * $\neq$ Christian Chicherio, $\ddagger$ Fabienne Collette, \\ *Christian Degueldre, *†Georges Franck, *†Gustave Moonen, and *†Eric Salmon
}

From the $*$ Cyclotron Research Center and the $\ddagger$ Department of Neuropsychology, University of Liège, and the $\dagger$ Department of Neurology, CHU Liège, Liège, Belgium; and the §Cognitive Psychopathology Unit, University of Geneve, Geneve, Switzerland.

\begin{abstract}
Summary: The goal of this study was to explore in patients with Alzheimer's disease (AD) the brain correlates of free and cued recall performance using an adaptation of the procedure developed by Grober and Buschke (1987). This procedure, which ensures semantic processing and coordinates encoding and retrieval, has been shown to be very sensitive to an early diagnosis of AD. Statistical parametric mapping (SPM 99) was used to establish clinicometabolic correlations between performance at free and cued verbal recall and resting brain metabolism in 31 patients with AD. Results showed that patient's score on free recall correlated with metabolic activity in right frontal regions (BA 10 and BA 45), suggesting that performance reflected a strategic retrieval attempt. Poor retrieval performance was tentatively attributed to a loss of functional correlation between frontal and medial temporal regions in patients with AD compared with elderly controls. Performance on cued recall was correlated to residual metabolic activity in bilateral parahippocampal regions (BA 36), suggesting that performance reflected retrieval of semantic associations, without recollection in AD. In conclusion, this study demonstrates that the diagnostic sensitivity for Alzheimer's disease of the cued recall performance in the Grober and Buschke procedure (1987) depends on the activity of parahippocampal regions, one of the earliest targets of the disease. Moreover, the results suggest that the poor performance of patients with AD during free and cued recall is related to a decreased connectivity between parahippocampal regions and frontal areas. Key Words: Episodic memory-Frontal areasParahippocampal regions-Alzheimer disease.
\end{abstract}

It is widely accepted that Alzheimer disease (AD) is associated with a severe impairment in episodic memory functioning, which is known to be present since the first stages of the disease and even in its preclinical phase (Morris, 1996).

Received February 7, 2002. Accepted September 10, 2002.

Supported by the Interuniversity Pole of Attraction (IAP) Program P5/04, Belgian State, Prime Minister's Office, Federal Office for Scientific, Technical and Cultural Affairs, the Belgian National Fund for Scientific Research (FNRS), the Research Fund of Liège University, and the Fondation Medical Reine Elisabeth (FMRE). F.L. is supported by the IAP. F.C. is a researcher at the FNRS.

Address correspondence and reprint requests to Dr. Françoise Lekeu, Center de Recherches du Cyclotron, University of Liège, Sart-Tilman, Bât. 30, B-4000 Liège, Belgium. E-mail: Francoise.Lekeu@ulg.ac.be
Memory impairment in AD affects free recall (Helkala et al., 1988; Grober et al, 2000), cued recall (Petersen et al., 1994; Buschke et al., 1995; Tounsi et al., 1999), and recognition (Branconnier et al., 1982; Wilson et al., 1983). These deficits have been considered as the consequence of poor encoding (Damasio et al., 1990; Köhler et al., 1998) and of retrieval impairment (Bird and Luszcz, 1991; Tuokko et al., 1991). Studies exploring storage in AD led to conflictual results because some of them claimed that the forgetting rate would be normal in AD (Kopelman, 1985; Becker et al., 1987, Money et al., 1992; Christensen et al., 1998), whereas other studies showed an accelerated forgetting rate in patients with AD compared with normal controls (Tröster et al., 1989; Welsh et al., 1991). 
From a diagnostic viewpoint, episodic memory tests are very useful in discriminating mild patients with $A D$ from normal elderly subjects (Bäckman and Small, 1998). More specifically, some studies demonstrated that episodic memory tests that provide more cognitive support both at encoding and retrieval are better predictors of dementia than tasks involving less cognitive support (Buschke et al., 1997; Small et al., 1997). For example, measures of cued recall, especially when the cues at retrieval matched those available at encoding, were reported to better discriminate between elderly controls and individuals with mild dementia than measures in which compatibility between learning and test phases was not maintained (Buschke et al., 1997).

In this context, Grober and Buschke (1987) developed the Free and Cued Selective Reminding Test (FCSRT), a memory procedure that was designed to combine both manipulation of the processing level during initial encoding and provision of specific cues for optimizing retrieval. In the learning phase, subjects are required to point to pictures of common objects corresponding to the semantic category given by the experimenter. After an interpolated task to avoid rehearsal, subjects are tested by successive trials of free and cued recall. The cued recall task was designed to facilitate retrieval of items not retrieved during free recall by supplying the same semantic cues as those offered during initial encoding. This congruence of semantic cues in both encoding and retrieval conditions places the subject in an optimal situation of encoding specificity (Tulving and Thomson, 1973). The procedure has been frequently used in the literature and has proved to be very sensitive to an early diagnosis of AD (Tuokko et al., 1991; Petersen et al., 1994; Tounsi et al., 1999), partly because patients with AD did not respond to the principle of encoding specificity as well as normal elderly controls. These studies showed that patients with early AD have impairments in both free and cued recall, compared with healthy elderly controls. The free recall performance during this task has been demonstrated to be a powerful measure for the prediction of future dementia (Grober et al., 2000). Moreover, the impaired ability of patients with AD to benefit from semantic cueing makes differential diagnosis with subcortical dementia possible, given that the latter patients have impaired free recall but are able to normalize their performance by cued recall (Pillon et al., 1993).

The predictive aspect of episodic memory tasks is consistent with neuropathologic and neuroimaging findings showing early changes in medial temporal volume in AD (Fox et al., 1996; Köhler et al., 1998; Laakso et al., 1998). However, recent studies indicate that episodic memory is subserved by a large network of cerebral re- gions, which can also be affected by the disease (Nyberg et al., 2000). The results from most studies in normal populations demonstrated the involvement of the prefrontal cortex and the "hippocampal formation" in the encoding (Grady et al., 1995; Stern et al., 1996) and retrieval processes (Squire et al., 1992; Nyberg et al., 1996) in episodic memory. Neuroimaging studies have also shown the involvement of many other structures, such as the temporoparietal association cortices, the cerebellum, and the cingulate cortex (Desgranges et al., 1998a). According to such a network organization, the episodic memory deficit in AD could be due not only to a functional impairment of these proper regions but also to defective connections between the different regions of this complex network. For example, neuropathologic data in AD highlighted a relative isolation of the hippocampal formation from other parts of the brain (Van Hoesen et al., 1991; Damasio et al., 1990). Various studies were conducted to better understand the neuronal basis of episodic memory impairment in AD (Becker et al., 1996; Herbster et al., 1996; Cardebat et al., 1998; Desgranges et al., 1998b; Bäckman et al., 1999). Globally, these studies showed that verbal episodic memory tasks in AD were related to activity in a large neuronal network, including structures classically described in functional activation studies in healthy subjects (Herbster et al., 1996; Desgranges et al., 1998a). According to the authors, similar activations observed in patients with $\mathrm{AD}$ and in normal elderly controls suggest that some of the regions involved in the episodic memory processes network would still be functional in early AD. Besides the activation of a common neuronal network for episodic retrieval in normal controls and patients with $\mathrm{AD}$, Bäckman et al. (1999) reported also specific activations in each group. Increases in activity observed in $\mathrm{AD}$, compared with healthy subjects, were interpreted in terms of compensatory reactions to the difficulties in performing the retrieval memory task.

Several MRI-based volumetric measurement studies in AD have more specifically explored the neuroanatomical correlates of different memory measures coming from the Grober and Buschke procedure (Deweer et al., 1995; De Toledo-Morrell et al., 2000). In particular, the total delayed recall score (mixed free and cued recall) was found to correlate with the hippocampal formation volume (Deweer et al., 1995). More recently, this memory procedure was used both in a verbal and a spatial form, and only free recall memory measures were selected for the analysis (De Toledo-Morrell et al., 2000). Left hippocampal volume was found to be the best predictor of verbal free recall performance, whereas right hippocampal volume was the best predictor of spa- 
tial free recall performance. With an adaptation of the same procedure, a clinicometabolic positron emission tomography (PET) study showed the left entorhinal cortex to be correlated to the summed score of three free recall trials (Eustache et al., 2001). But none of these studies explored the regions specifically associated to performance in cued recall.

Consequently, the aim of our study was to reexamine with PET the relationships between brain metabolism in $\mathrm{AD}$ and memory performances in an adaptation of the Grober and Buschke procedure (with printed words rather than labeled pictures). Our goal was to emphasize regions differentially associated to free and cued recall performance in $\mathrm{AD}$, with a particular interest to those related to cued recall performance, given the particular sensitivity of the semantic cueing procedure for the early diagnosis of $\mathrm{AD}$.

\section{METHODS}

\section{Participants}

Thirty-one subjects (10 males and 21 females) who met the NINCDS-ADRDA criteria for probable Alzheimer's disease underwent both a French adaptation of the Grober and Buschke procedure (1987) and resting (18F) fluorodeoxyglucose positron emission tomography (18FDG-PET). They all had dementia with progressive memory impairment (McKhann et al., 1984). The diagnosis was based on general medical, neurologic, complete neuropsychologic examination and clinical followup. The Grober and Buschke (1987) procedure was included in the first diagnostic neuropsychological testing, and patients were not yet taking medication that might affect cognition (either cholinesterase inhibitors or psychoactive medications) at the time of testing. The CT scan showed at most mild atrophy. Mean age was 70.9 years (SD 6.1 years), and mean disease duration was 31.8 months (SD 23.2 months). Mean score at Mini Mental State Examination (MMSE) (Folstein et al., 1975) was 21.9 (SD 4.0). Three of the 31 patients had possible AD at the time of the study, but they met criteria for probable AD after longitudinal follow-up.

Two control populations were selected. The first control population underwent the memory test but not the PET scan. In contrast, the second group of control subjects did not receive the memory task, but they were selected from our database of 18FDG-PET. The first control population comprised 31 elderly subjects (11 males and 20 females). Mean age of this control population was 69.4 years (SD 4.2 years; range 60-78 years). Age was not significantly different between AD and control populations $[t(60)=1.14, p=0.257]$. The second group of control subjects consisted of 20 elderly subjects (15 males and 5 females). Mean age was 64.45 years (SD 5.79 years; range 56-71 years). There was a statistical difference between the age of AD and the control subjects $[t(49)=3.763, p<0.0005]$. For this reason, age was taken as a confounding covariate in statistical analyses.

\section{Materials}

The episodic memory test used was a French adaptation (Van der Linden et al., 2001) of the procedure designed by Grober and Buschke (1987). Contrary to the original version which used labeled pictures, the adaptation developed in this study used printed words. In this test, 16 words had to be learned. They were presented to the subject on four different cards, each with four items. The subject was asked to point to and to read aloud each item (e.g., daffodil) when the name of its category was verbally given as cue (e.g., flower). When all four items on a card were correctly named, the card was removed and immediate verbal cued recall was tested, in the order of identification, by giving each category cue to the subject (e.g., what was the flower?). If the patient was unable to recall an item in response to its cue, the pointing and naming procedure was performed again for this item, and cued recall was tested again until a correct response was given. Once the immediate cued recall for a group of four items was completed, the next set of items was presented. The learning phase of the 16 items was followed by $20 \mathrm{~s}$ of counting backwards to avoid the recency (short-term memory) effect. This interference task was followed by a free recall trial for all 16 items, and a cued recall trial for those items not retrieved at free recall, and for which the same semantic cues as those used during encoding were verbally given. Three recall trials and a 20-min delayed free and cued recall task were administered. Individual scores on both free and cued recall were computed in the current study, taking first and delayed trials into account.

\section{Image Processing of PET Data}

All images of cerebral glucose uptake were obtained in the resting condition on a SIEMENS CTI 951 R 16/31 tomograph (CTI, Knoxville, TN, USA) in twodimensional mode with collimating septa extended, using the ${ }^{18}$ fluorodeoxyglucose (18FDG) technique. The camera had a $10.8-\mathrm{cm}$ field of view in the axial direction. A 20-min transmission scan was acquired for attenuation correction using three ${ }^{68} \mathrm{Ge}$ rotating sources prior to the tracer injection. An 8-mCi intravenous bolus injection of 18FDG was followed 35 min later by 20 -min acquisition 
of the emission data under standard conditions (eyes closed in dimmed ambient light and ears unplugged). This scan was then reconstructed using a Hanning filter at a cutoff frequency of 0.5 cycles per pixel, giving a transaxial resolution of $8.7 \mathrm{~mm}$ full-width at halfmaximum for each of the 31 planes.

All calculations and image transformations were carried out on a SUN SPARC Ultra 60 workstation (Sun Computers Europe Inc., Surrey, UK). For each PET scan, the 31 transverse planes were interpolated to 44 planes to render the voxels cubic $(2.347 \times 2.347 \times 2.347)$. All subsequent steps of image processing were made using the statistical parametric mapping software (SPM99, Wellcome Department of Cognitive Neurology, London, UK) implemented in Matlab 5.3 (Math Works, Natick, MA, USA). First, PET images were manually reoriented to the interhemispheric fissure and intercommissural plane. Functional imaging data were then normalized into a standard stereotaxic anatomic space (Talairach and Tournoux, 1988), using a bilinear interpolation method to allow for intersubject averaging. The normalizing spatial transformation matches (in a least squared sense) each scan to a template image that already conforms to the standard anatomic space. The estimation of spatial normalization parameters consists of two parts: affine registration and basis function. All images were checked visually before and after the normalization procedure to ensure that no cerebral region was incorrectly normalized in the stereotaxic anatomic space. All scans were finally smoothed using an isotropic Gaussian filter 12 mm full-width half-maximum (Signorini et al., 1999) to increase the signal-to-noise ratio, to account for differences in gyral anatomy in the data set, and to conform more closely to a Gaussian field model (statistical inferences made in the following imaging analyses rely on the theory of Gaussian fields).

\section{Analysis of PET Data}

Proportional scaling was used to achieve global normalization of voxel values between scans mainly to remove effects of differences in global cerebral metabolism between scans. To test hypotheses about regionally specific effects, the parameters were estimated in the general linear model (Frackowiak et al., 1997) at each and every voxel included in the analysis. The statistical program (SPM99) generated a group-specific adjusted mean value and an associated adjusted error variance for each voxel. The resulting statistics were expressed by the $t$ distribution. The $t$ values constituted an SPM $(t)$. Results were thresholded to a $t$ statistic $(p<0.001-0.01)$ to assess statistical significance with a priori hypotheses. Age and MMSE score were introduced as nuisance vari- ables in all SPM design matrices, except for interregional correlations analysis where only age was taken as a nuisance variable.

The statistical analyses performed in SPM99 were: a correlational analysis between brain metabolism and recall (free and cued recall) in AD and interregional correlations between some specific areas and whole brain metabolism with interaction effect between the $\mathrm{AD}$ group and the group of 20 elderly controls from our database.

\section{RESULTS}

\section{Neuropsychologic Data}

Neuropsychological performances were compared with those obtained in the first group of 31 elderly controls. The analysis was carried out on performances in the first and delayed trials of free and cued recall. Performance in free and cued recall was expressed as proportions of items recalled. For free recall, the proportion represents the number of items freely recalled/16 (maximal number of items). For cued recall, the proportion represents the number of items recalled among those not retrieved during free recall/the number of words not recalled during free recall.

Mean proportions of items recalled during free and cued recall at first trial for 31 patients with $\mathrm{AD}$ were, respectively, 19.5\% (SD 12.7\%) and 35.2\% (SD 21.2\%). These performances were significantly lower than those obtained by control subjects [respectively, mean $53.5 \%$, SD $15.7 \%$ for first free recall, $t(60)=-9.36, p<$ 0.0001 ; and mean $86.9 \%$, SD $15.0 \%$ for first cued recall, $t(60)=-11.06, \mathrm{p}<0.0001]$. Mean proportions of words recalled during delayed free and cued recall in the $\mathrm{AD}$ population were respectively $16.0 \%$ (SD $15.3 \%$ ) and $37.0 \%$ (SD 23.9\%). These performances were also significantly lower than those in control subjects [respectively, mean $71.0 \%$, SD $15.5 \%$ for delayed free recall, $t$ $(60)=-14.09, p<0.0001$; and mean $95.6 \%$, SD $8.5 \%$ for delayed cued recall, $t(60)=-72.8, p<0.0001]$ (Table 1).

\section{Correlation Between Brain Metabolism and Free Versus Cued Recall Performance}

The first comparison was designed to explore the cerebral regions that were more related to free recall performance than to cued recall score during the first trial. This direct comparison showed a positive correlation with the right superior frontal gyrus (BA 10). When correlations with first and delayed free recall were respectively contrasted to those with first and delayed cued 
TABLE 1. Mean performance during free and cued recall in $A D$ patients and elderly controls, expressed in proportions (standard deviation)

\begin{tabular}{lcc}
\hline & $\begin{array}{c}\text { Patients } \\
\text { with AD }\end{array}$ & $\begin{array}{c}\text { Elderly } \\
\text { controls }\end{array}$ \\
\hline First free recall & $19.5(12.7)$ & $53.5(15.7)^{*}$ \\
First cued recall & $35.2(21.2)$ & $86.9(15.0)^{*}$ \\
Delayed free recall & $16.0(15.3)$ & $71.0(15.5)^{*}$ \\
Delayed cued recall & $37.0(23.9)$ & $95.6(8.5)^{*}$ \\
\hline
\end{tabular}

*Significant difference at $p<0.0001$.

recall and when results were entered into a conjunction analysis (designed to highlight common cerebral regions specifically related to free recall performances), a positive correlation appeared not only in the right superior frontal gyrus (BA 10) but also in the right inferior frontal gyrus (BA 45) (Fig. 1; Table 2).

The second analysis aimed to explore the cerebral regions more implicated in cued recall than in free recall in the first trial. There was a positive correlation with left and right parahippocampal regions (BA 36). These results were subsequently confirmed when correlations with first and delayed cued recall were respectively compared with those with first and delayed free recall and then entered into a conjunction analysis (Fig. 2; Table 2).

\section{Interregional Correlations}

Interregional metabolic correlations were analyzed in SPM using covariates of interest. For each scan, a covariate of interest corresponded to the relative metabolic value obtained in a voxel of interest. This analysis allowed to emphasize the degree of association in our AD and control populations between functional activity in a given voxel and metabolism in the other regions of the brain. Individual metabolic values of the most significant regions obtained in the previous analyses (BA 36 and BA $45)$ were selected in the $\mathrm{AD}$ and in the control populations. Interregional covariance analysis was computed for both groups, using individual glucose metabolism in BA 36 and BA 45 as the variable of interest in a single matrix and age as confounding covariate. Networks of functionally related brain regions were emphasized in patients with $\mathrm{AD}$ and elderly controls on SPM thresholded at $p<0.01$ and $p<0.001$ (Table 3). Correlations were significantly greater in controls than in patients with $\mathrm{AD}$ between the left parahippocampal gyrus (BA 36 ), on the one hand, and the right inferior frontal gyrus (BA 45 and BA 47) on the other. Correlations were also greater in controls than in patients with $\mathrm{AD}$ between the right inferior frontal gyrus (BA 45) and two other left frontal areas (BA 46 and BA 6), right temporal and pa-
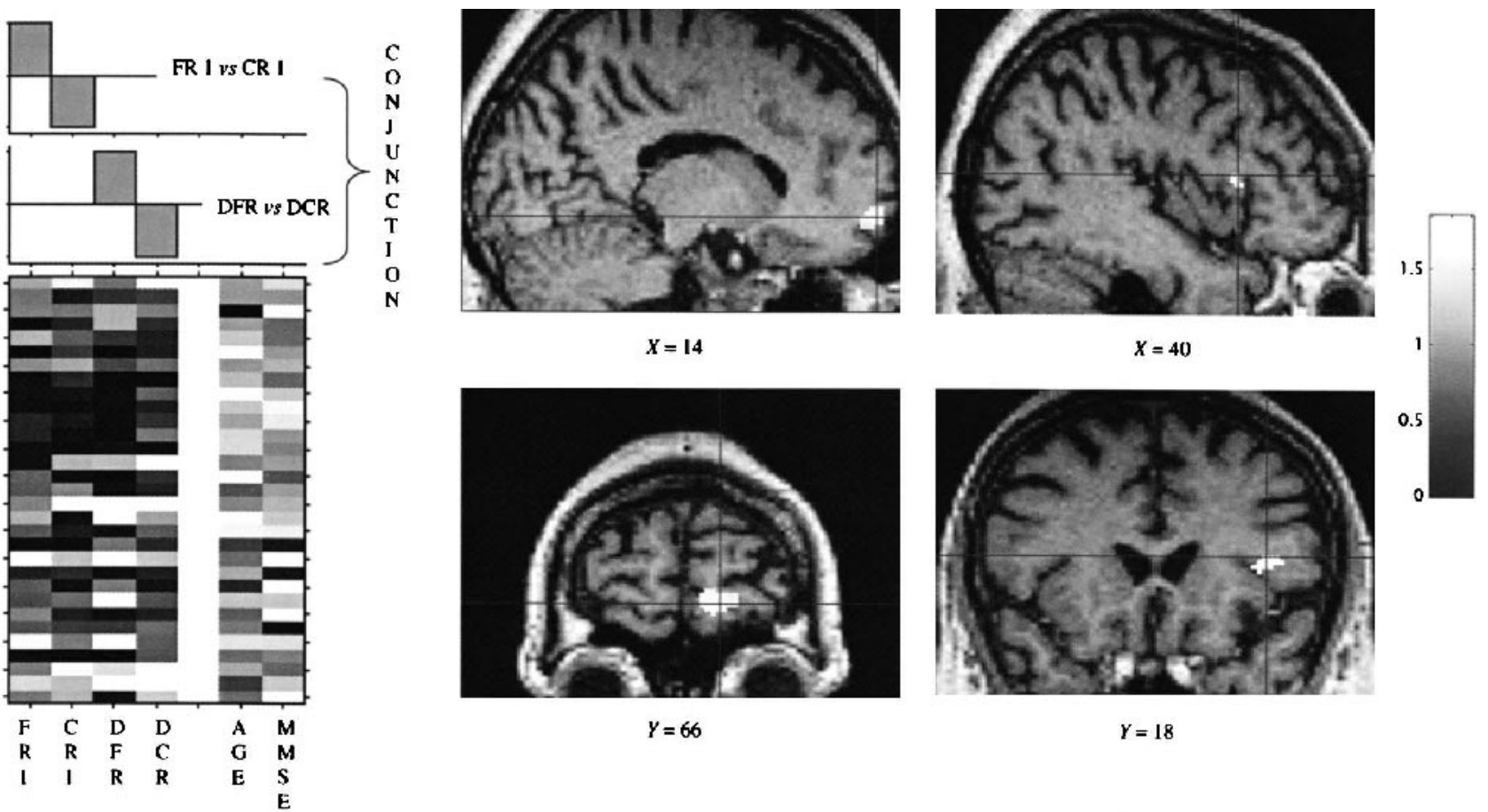

FIG. 1. Results from SPM99 analysis in patients with AD. The conjunction analysis between first (Free vs. Cued Recall) and Delayed (Free vs. Cued Recall) highlights the cerebral regions where relative brain glucose uptake is positively correlated with free recall more than cued recall performance. Significant correlation in two right frontal regions (BA 10 and BA 45) is shown as colored voxels projected upon corresponding T1-weighted MRI of one AD patient. 
TABLE 2. Correlations between brain metabolism and free versus cued recall in AD patients

\begin{tabular}{|c|c|c|c|c|}
\hline & $\mathrm{x}$ & $\mathrm{y}$ & $\mathrm{z}$ & $\mathrm{Z}$ score \\
\hline \multicolumn{5}{|l|}{ Free recall } \\
\hline \multicolumn{5}{|l|}{ First free recall versus first cued recall } \\
\hline R superior frontal gyrus (BA10) & 14 & 68 & -10 & 2.53 \\
\hline \multicolumn{5}{|c|}{ Conjunction between first and delayed free recall (vs. cued recall) } \\
\hline $\mathrm{R}$ inferior frontal gyrus (BA 45) & 40 & 18 & 12 & 2.96 \\
\hline $\mathrm{R}$ superior frontal gyrus (BA10) & 14 & 66 & -8 & 2.58 \\
\hline R superior frontal gyrus (BA 10) & 28 & 60 & -2 & 2.52 \\
\hline R superior frontal gyrus (BA 10) & 16 & 64 & 18 & 2.39 \\
\hline \multicolumn{5}{|l|}{ Cued recall } \\
\hline \multicolumn{5}{|l|}{ First cued recall versus first free recall } \\
\hline L parahippocampal gyrus (BA 36) & -32 & -26 & -18 & 2.96 \\
\hline R parahippocampal gyrus (BA 36) & 34 & -34 & -16 & 2.96 \\
\hline \multicolumn{5}{|c|}{ Conjunction between first and delayed cued recall (vs. free recall) } \\
\hline L parahippocampal gyrus (BA 36) & -32 & -26 & -18 & $3.16^{*}$ \\
\hline R parahippocampal gyrus (BA 36) & 32 & -38 & -16 & 2.93 \\
\hline
\end{tabular}

$\mathrm{AD}=$ Alzheimer's disease $; \mathrm{BA}=$ Brodmann's area; $\mathrm{x}, \mathrm{y}$ and $\mathrm{z}$ are coordinates in the stereotactical space of Talairach and Tournoux (1988).

Statistical parameteric maps were thresholded to $p<0.01$ or $p<0.001 *$ (uncorrected) with age and MMSE as confounding covariates.

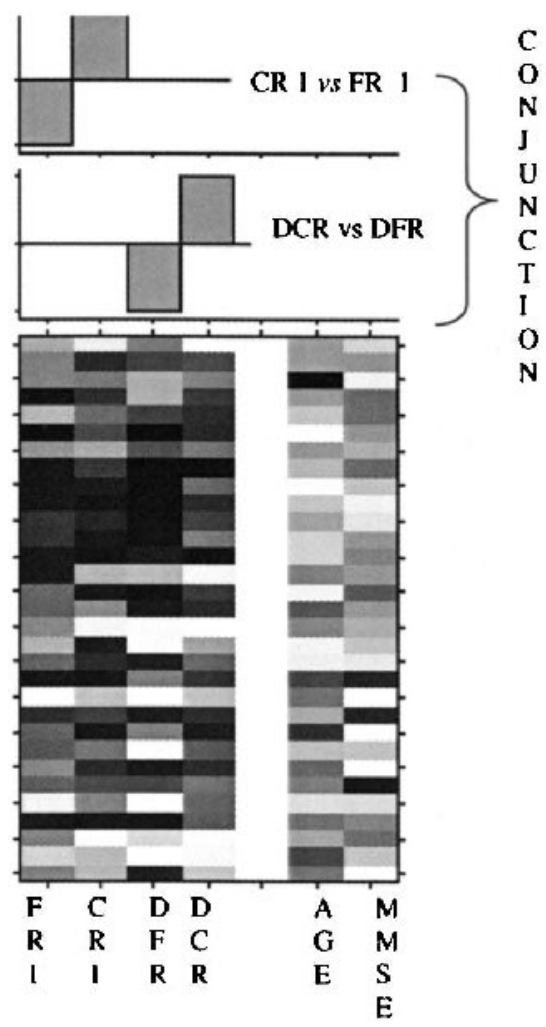

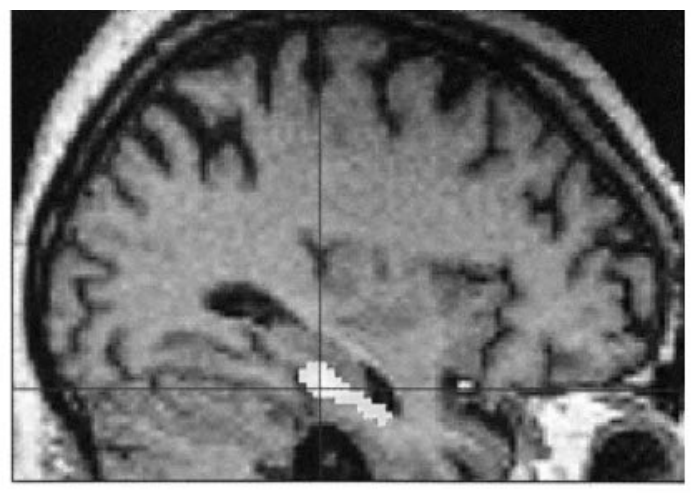

$x=-32$

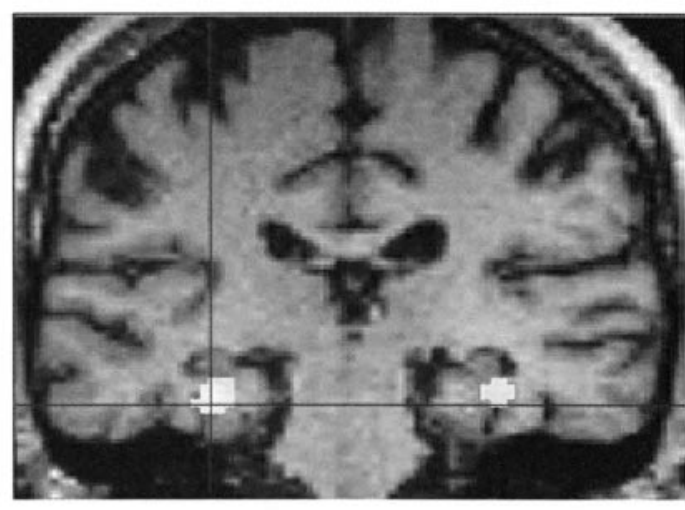

$Y=-26$

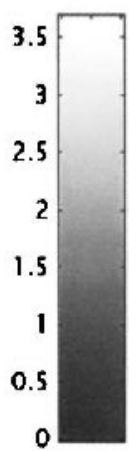

FIG. 2. Results from SPM99 analysis in patients with AD. The conjunction analysis between first (Cued vs. Free Recall) and Delayed (Cued vs. Free Recall) highlights the cerebral regions where relative brain glucose uptake is positively correlated with cued recall more than free recall performance. Significant correlation in bilateral parahippocampal regions (BA 36) is shown as colored voxels projected upon corresponding T1-weighted MRI of one AD patient. 
TABLE 3. Interregional correlations greater in healthy elderly controls than in patients with $A D$

\begin{tabular}{|c|c|c|c|c|}
\hline & $\mathrm{x}$ & $\mathrm{y}$ & $\mathrm{z}$ & $\mathrm{Z}$ score \\
\hline \multicolumn{5}{|c|}{$\begin{array}{l}\text { Interregional correlations between left parahippocampal gyrus (BA 36) and } \\
\text { brain metabolism ( } p<0.001 \text {; uncorrected) }\end{array}$} \\
\hline R superior frontal gyrus (BA 45) & 56 & 20 & 10 & 3.14 \\
\hline $\mathrm{R}$ inferior frontal gyrus (BA 47) & 44 & 32 & -4 & 2.98 \\
\hline \multicolumn{5}{|c|}{$\begin{array}{l}\text { Interregional correlations between right inferior frontal gyrus (BA } 45) \text { and } \\
\text { brain metabolism }(p<0.01 \text {; uncorrected; tentatively reported) }\end{array}$} \\
\hline L middle frontal gyrus (BA 46) & -50 & 30 & 22 & 3.00 \\
\hline L middle frontal gyrus (BA 6) & -26 & 14 & 54 & 2.92 \\
\hline $\mathrm{R}$ inferior temporal gyrus (BA 20) & 44 & -20 & -20 & 2.88 \\
\hline $\mathrm{R}$ inferior parietal lobule (BA 40) & 44 & -36 & 46 & 2.75 \\
\hline L parahippocampal gyrus (BA 36) & -42 & -38 & -12 & 2.33 \\
\hline
\end{tabular}

$\mathrm{AD}=$ Alzheimer's disease; $\mathrm{BA}=$ Brodmann's area; $\mathrm{x}, \mathrm{y}$ and $\mathrm{z}$ are coordinates in the stereotactical space of Talairach and Tournoux (1988).

rietal regions (respectively, BA 20 and BA 40) and the left parahippocampal region (BA 36).

\section{DISCUSSION}

The purpose of this study was to emphasize cerebral regions related to $\mathrm{AD}$ memory performances in an adaptation of the Grober and Buschke (1987) procedure and, more specifically, to contrast the regions differentially associated to free and cued recall performances.

The behavioral data indicated a marked deficit for patients with $\mathrm{AD}$ in both first and delayed free and cued recall trials. So, the pattern of performance of patients with $\mathrm{AD}$ showed a lower score in free recall and a poorer benefit of the semantic cueing, compared with healthy control subjects. As opposed to the patients with $\mathrm{AD}$, healthy elderly subjects effectively tended to maximize performances in the cueing condition. All these findings are in agreement with previous neuropsychological studies (Grober et Buschke, 1987; Grober et al., 1988; Tuokko et al., 1991; Pillon et al., 1993; Tounsi et al., 1999).

Concerning free recall, clinicometabolic correlations between resting brain metabolism and free recall (compared to cued recall) performance in the first trial in patients with $\mathrm{AD}$ showed a positive correlation with the right superior frontal gyrus (BA 10). This observation was corroborated in the conjunction analysis with the delayed free recall (contrasted to cued recall) performance, which showed an additional correlation with the right inferior frontal gyrus (BA 45). This result is in agreement with the few imaging studies that explored cerebral regions involved in free recall performance of normal subjects (Grasby et al., 1993; Petrides et al., 1995; Fletcher et al., 1998) showing that free recall of verbal information activated prefrontal regions either on the right side or bilaterally. Our results are also in agreement with most PET activation studies in control popu- lations that have yielded unilateral right prefrontal activation during any type of retrieval (Tulving et al., 1994 for the HERA model; Cabeza and Nyberg, 1997). Moreover, numerous studies in normal subjects suggested that the prefrontal cortex (especially on the right side) is implicated in search activity during memory tasks (Cabeza et al., 1997). Consequently, the relationship between right frontal metabolism and $\mathrm{AD}$ patients' free recall performance is consistent with activation studies, suggesting that the network used by patients with AD would be similar to that used by healthy controls (Herbster et al., 1996). However, a multistudy analysis of PET data (Lepage et al., 2000) identified the right superior frontal region (with coordinates very similar to those found in the current study) as part of a set of cerebral regions where neuronal activity would appear to be correlated with the maintenance of episodic memory retrieval mode, which corresponds to the retrieval attempt, independently of the success of this attempt. Moreover, some speculations can be made concerning the absence of significant correlation between free recall performance and left frontal regions in patients with AD. According to the CARA model (Nolde et al., 1998), the involvement of the left prefrontal regions during episodic retrieval would depend upon the complexity of the episodic retrieval task, like initiating strategies or generating cues for retrieving information. Based upon this suggestion, the absence of significant correlation with the left frontal areas in the free recall of patients with $\mathrm{AD}$ could reflect the absence of such self-initiated retrieval strategies required to have a good free recall performance. However, PET activation studies in $\mathrm{AD}$ are needed to test more directly this later hypothesis.

From a neuropsychological viewpoint, all these findings are in keeping with studies demonstrating that frontal lobe lesions disturbed free recall performance in epi- 
sodic tasks (Jetter et al., 1986), this impaired performance being more frequent for free recall than for cued recall or recognition (Wheeler et al., 1995). Moreover, performance during free recall would crucially depend on strategic retrieval processes, i.e., the ability for the subject to generate its own contextual cues to retrieve the studied items. The poor performance of patients with AD in free recall showed that patients were impaired in the use of these recall strategies. In agreement with some studies suggesting that prefrontal regions are implicated in the strategies of retrieval in memory (Moscovitch, 1996), the clinicometabolic correlations between performance during free recall and brain metabolism suggest that at least BA 10 would be involved in the installation of such processes of retrieval.

With regard to cued recall in patients with $\mathrm{AD}$, clinicometabolic correlations showed a positive relationship between cued recall performance and activity in bilateral parahippocampal regions. In neuroimaging studies with normal subjects, parahippocampal regions were found to be activated in word and picture associative and visual semantic tasks (Vandenberghe et al., 1996), in associative recognition compared with old item recognition (Yonelinas et al., 2001), in semantic matching recognition tasks (Ricci et al., 1999), and in semantic compared with episodic retrieval (with coordinates similar to those found in our study) (Wiggs et al., 1999). More specifically, parahippocampal activations were described in cued recall tasks, using a word stem completion paradigm (Squire, 1992; Buckner et al., 1995; Schacter et al., 1996; Heckers et al., 1998). In this type of task, subjects are presented with a list of words and are subsequently asked to complete three letter stems by retrieving study list words. The recall of words compared with a baseline condition was shown to activate the right prefrontal cortex and the right hippocampal and parahippocampal gyri (Squire, 1992). However, when the recall of words was compared after high encoding of words (semantic judgement $=$ high recall condition) and after shallow encoding of words (perceptual judgement $=$ low recall condition), hippocampal activation was found only for high recall (both vs. baseline and vs. low recall) (Schacter et al., 1996; Heckers et al., 1998). Right prefrontal cortex activation was observed during recall of words by a word stem completion, but right hippocampal/parahippocampal activation occurred when the cases of words during retrieval (e.g., uppercase letters) were the same as those presented during encoding, corresponding to the principle of encoding specificity.

Taken together, these studies pointed to the importance of the semantic memory component of tasks for parahippocampal activations (Schacter et al., 1996).
Moreover, encoding specificity would be an important factor allowing to demonstrate parahippocampal regions' involvement in memory processes (Buckner et al., 1995). Because the current study promoted semantic processing during encoding and optimized the specificity encoding effect (by giving the same semantic cues during cued recall as during encoding), the results highlighted the importance of both factors in the correlation between cued recall performance and parahippocampal metabolism.

From a neuropsychological viewpoint, two different types of processes, which would depend on distinct cerebral structures, carry out episodic memory retrieval in recognition condition (Reed and Squire, 1997; Mishkin et al., 1998). On the one hand, recollection processes allow access to contextual information and would depend upon both hippocampal and frontal regions. On the other hand, a semantic retrieval process, free from contextual aspects, is the basis of familiarity-based retrieval and would be mediated by parahippocampal regions. In patients with $\mathrm{AD}$, recollection processes would be impaired by difficulties to access contextual information (Fox et al., 1998). However, familiarity-based judgments are said to be relatively preserved in AD (Koivisto et al., 1998). By analogy, we suggest that during cued recall, the process of retrieval of patients with $\mathrm{AD}$ would be based only upon the semantic characteristics of the given categorical cue to produce an exemplar semantically associated with this category. But, given that recollection processes are impaired in the disease, patients with $\mathrm{AD}$ would not use contextual information to check whether the item retrieved is matched to the target. This would be the reason why patients with $\mathrm{AD}$ make frequent intrusive errors in cued recall tasks (Tounsi et al., 1999), and this would explain the lower level of accuracy in cued recall compared with normal controls. Our results showing a correlation between cued recall performance and parahippocampal regions in patients with $\mathrm{AD}$ are in line with the hypothesis concerning the parahippocampal role in a memory free of contextual aspects, like semantic memory (Ricci et al., 1999; Wiggs et al., 1999). To summarize, our suggestion is that patients with AD responded to semantic cueing by a conceptual priming effect. In other words, when given a specific cue, patients with $\mathrm{AD}$ would produce the first semantically associated item coming to mind and would not have access to the contextual features of the target item to check information. On the contrary, cued recall performance of healthy elderly subjects would capitalize not only on the use of semantic memory underlain by parahippocampal regions but also on retrieval of contextual information underlain by frontal and hippocampal networks. These hypotheses are consistent with the proposition of several authors 
postulating that different regions of the medial temporal lobe support different roles in memory functioning (Vargha-Khadem et al., 1997; Mishkin et al., 1998; Tulving and Markowitsch, 1998). In particular, the acquisition of semantic associations would depend upon surrounding hippocampal structures (perirhinal, parahippocampal, and entorhinal regions), whereas the retrieval of episodic (contextual) information would depend upon hippocampal regions, along with frontal areas.

Interregional correlations were greater in elderly controls than in patients with $\mathrm{AD}$ between right inferior frontal activity and left middle frontal gyri, right inferior temporal gyrus, right inferior parietal lobule, and left parahippocampal gyrus metabolism. These observations would reflect functional disconnection in $\mathrm{AD}$, within frontal structures on the one hand (Becker et al., 1996) and between frontal cortex and temporoparietal and parahippocampal regions on the other hand (Horwitz et al., 1987; Azari et al., 1992; Leuchter et al., 1992). The reverse pattern of disconnection of frontal areas from parahippocampal regions was also observed because we showed greater interregional correlations in elderly controls between the left parahippocampal metabolism and the right inferior frontal activity. Interestingly, in a functional connectivity study of episodic memory retrieval (McIntosh et al., 1997), frontal activity of the right BA 45/BA 47 was found to be functionally connected with that in the left parahippocampal region only when the retrieval in memory was successful, and success was greater because the encoding was deeper (semantic). Our results, showing a greater correlation between the left parahippocampal gyrus and the right inferior frontal gyrus (BA 45) in healthy elderly subjects than in patients with $\mathrm{AD}$, would reflect an impaired functional connectivity between both regions in $\mathrm{AD}$ accounting for poor successful retrieval in recall performance. These results are in keeping with the disconnection hypothesis in AD, which postulates that memory problems of patients with $\mathrm{AD}$ would be the consequence not only of lesions in specific areas but also of disruption of interactions between specific brain areas involved in memory (Hyman et al., 1984; Van Hoesen et al., 1991).

Acknowledgments. We also thank two anonymous reviewers for their very helpful comments on an earlier version of the manuscript.

\section{REFERENCES}

Azari NP, Rapoport SI, Grady CL, et al. Patterns of interregional correlations of cerebral glucose metabolic rates in patients with dementia of the Alzheimer type. Neurodegeneration 1992;1:101-1.

Bäckman L, Small BJ. Influences of cognitive support on episodic remembering: tracing the process from normal aging to Alzheimer's disease. Psychol Aging 1998;13:267-76.

Bäckman L, Andersson JLR, Nyberg L, et al. Brain regions associated with episodic retrieval in normal aging and Alzheimer's disease. Neurology 1999;52:1861-70.

Becker JT, Boller F, Lopez OL, et al. Normal rates of forgetting of verbal and non-verbal material in Alzheimer's disease. Cortex 1987; 23:59-72.

Becker JT, Mintun MD, Aleva K, et al. Compensatory reallocation of brain resources supporting verbal episodic memory in Alzheimer's disease. Neurology 1996;46:692-700.

Bird M, Luszcz M. Encoding specificity, depth of processing, and cued recall in Alzheimer's disease. J Clin Exp Neuropsychol 1991;13: $508-20$

Branconnier RJ, Cole JO, Spera KF, et al. Recall and recognition as diagnostic indices of malignant memory loss in senile dementia: a bayesian analysis. Exp Aging Res 1982;8:189-93.

Buckner RL, Petersen SE, Ojemann JG, et al. Functional anatomic studies of explicit and implicit memory retrieval tasks. J Neurosci 1995;15:12-29.

Buschke G, Sliwinski M, Kuslansky G, et al. Aging, encoding specificity, and memory change in the Double Memory Test. J Int Neuropsychol Soc 1995;1:483-93.

Buschke H, Sliwinski MJ, Kuslansky G, et al. Diagnosis of early dementia by the double memory test: encoding specificity improves diagnostic sensitivity and specificity. Neurology 1997;48:989-97.

Cabeza R, Kapur S, Craik FIM, et al. Functional neuroanatomy of recall and recognition: a PET study of episodic memory. $J$ Cogn Neurosci 1997;9:277-88

Cabeza R, Nyberg L. Imaging cognition: an empirical review of PET studies with normal subjects. J Cogn Neurosci 1997;9:1-26.

Cardebat D, Démonet J-F, Puel M, et al. Brain correlates of memory processes in patients with dementia of Alzheimer's type: a SPECT activation study. J Cereb Blood Flow Metab 1998;18:457-62.

Christensen H, Kopelman MD, Stanhope N, et al. Rates of forgetting in Alzheimer dementia. Neuropsychologia 1998;36:547-57.

Damasio AR, Van Hoesen GW, Hyman BT. Reflections on the selectivity of neuropathologic changes in Alzheimer's disease. In: Schwartz MN, ed. Modular Deficits in Alzheimer Type Dementia. Cambridge: MIT Press, 1990:83-100.

Desgranges B, Baron J-C, Eustache F. The functional neuroanatomy of episodic memory: the role of the frontal lobes, the hippocampal formation, and other areas. Neuroimage 1998a;8:198-213.

Desgranges B, Baron JC, de la Sayette V, et al. The neural substrates of memory systems impairment in Alzheimer's disease. Brain 1998b;121:611-31.

De Toledo-Morrell L, Dickerson B, Sullivan MP, et al. Hemispheric differences in hippocampal volume predict verbal and spatial memory performance in patients with Alzheimer's disease. Hippocampus 2000;10:136-42.

Deweer B, Lehericy S, Pillon B, et al. Memory disorders in probable Alzheimer's disease: the role of hippocampal atrophy as shown with MRI. J Neurol Neurosurg Psychiatry 1995;58:590-97.

Eustache F, Desgranges B, Giffard B, et al. Entorhinal cortex disruption causes memory deficit in early Alzheimer's disease as shown by PET. Neuroreport 2001;12:683-5.

Fletcher PC, Shallice T, Frith CD, et al. The functional roles of prefrontal cortex in episodic memory: II. Retrieval. Brain 1998;121: 1249-56.

Folstein MF, Folstein SE, McHugh PR. Mini Mental State: a practical method for grading the cognitive state of patients for the clinicians. J Psychiatry Res 1975;12;189-98.

Fox NC, Warrington EK, Freeborough PA. Presymptomatic hippocampal atrophy in Alzheimer's disease: a longitudinal MRI study. Brain 1996;119:2001-7.

Fox NC, Warrington EK, Seiffer AL, et al. Presymptomatic cognitive deficits in individuals at risk for familial Alzheimer's disease: a longitudinal prospective study. Brain 1998;121:1631-9. 
Frackowiak RSJ, Friston KJ, Frith CD, et al. Human Brain Function. San Diego: Academic Press, 1997.

Grady CL, McIntosh AR, Horwitz B, et al. Age-related reductions on human recognition memory due to impaired encoding. Science 1995; 269:218-21.

Grasby PM, Frith CD, Friston KJ, et al. A graded task approach to the functional mapping of brain areas implicated in auditory-verbal memory. Brain 1993;117:1271-82.

Grober E, Buschke H. Genuine memory deficits in dementia. Dev Neuropsychol 1987;3:13-36.

Grober E, Buschke H, Crystal H, et al. Screening for dementia by memory testing. Neurology 1988;38:900-3.

Grober E, Lipton RB, Hall C, et al. Memory impairment on free and cued selective reminding predicts dementia. Neurology 2000;54: 827-32.

Heckers S, Rauch SL, Goff D, et al. Impaired recruitment of the hippocampus during conscious recollection in schizophrenia. Nat $\mathrm{Neu}$ rosci 1998;1:318-23.

Helkala EL, Laulumaa V, Soininen H, et al. Recall and recognition memory in patients with Alzheimer's disease and Parkinson's disease. Ann Neurol 1988;24:214-7.

Herbster AN, Nichols T, Wiseman MB, et al. Functional connectivity in auditory-verbal short-term memory in Alzheimer's disease. $\mathrm{Neu}$ roimage 1996;4:67-77.

Horwitz B, Grady CL, Sclageter NL, et al. Intercorrelations of regional glucose metabolic rates in Alzheimer's disease. Brain Res 1987;407: 294-306.

Hyman BT, Van Hoesen GW, Damasio AR, et al. Alzheimer's disease: cell-specific pathology isolates the hippocampal formation. Science 1984;225:1168-70.

Jetter W, Poser U, Freeman RB, et al. A verbal long term memory deficit in frontal lobe damaged patients. Cortex 1986;22:229-42.

Köhler S, Black SE, Sinden M, et al. Memory impairments associated with hippocampal versus parahippocampal-gyrus atrophy: an MR volumetry study in Alzheimer's disease. Neuropsychologia 1998;36: 901-14.

Koivisto M, Portin R, Seinelä A, et al. Automatic influences of memory in Alzheimer's disease. Cortex 1998;3:209-19.

Kopelman MD. Rates of forgetting in Alzheimer-type dementia and Korsakoff's syndrome. Neuropsychologia 1985;23:623-38.

Laakso MP, Soininen H, Partanen K, et al. MRI of the hippocampus in Alzheimer's disease: sensitivity, specificity and analysis of the incorrectly classified subjects. Neurobiol Aging 1998;19:23-31.

Lepage M, Ghaffar O, Nyberg L, et al. Prefrontal cortex and episodic memory retrieval mode. Proc Natl Acad Sci USA 2000;97:506-11.

Leuchter AF, Newton TF, Cook IA, et al. Changes in brain functional connectivity in Alzheimer-type and multi-infarct dementia. Brain 1992;115:1543-61.

McIntosh AR, Nyberg L, Bookstein FL, et al. Differential functional connectivity of prefrontal and medial temporal cortices during episodic memory retrieval. Hum Brain Mapp 1997;5:323-7.

McKhann G, Drachman D, Folstein M, et al. Clinical diagnosis of Alzheimer's disease: report of the NINCDS-ADRDA Work Group under the auspice of Department of Health and Human Services Task Force on Alzheimer's disease. Neurology 1984;34:939-44.

Mishkin M, Vargha-Khadem F, Gadian DG. Amnesia and the organization of the hippocampal system. Hippocampus 1998;8:212-16.

Money EA, Kirk RC, McNaughton N. Alzheimer's dementia produces a loss of discrimination but no increase in rate of memory decay in delayed matching to sample. Neuropsychologia 1992;30:133-43.

Morris RG. The Cognitive Neuropsychology of Alzheimer-Type Dementia. New York: Oxford Univerisity Press, 1996.

Moscovitch M. La mémoire et le travail avec la mémoire: evaluation d'un modèle en composantes de traitement et comparaisons avec d'autres modèles. In: Schacter DL, Tulving E, eds. Systèmes de mémoire chez l'animal et chez l'homme. Marseille: Solal,1996:265304.
Nolde SF, Johnson MK, Raye CR. The role of prefrontal cortex during tests of episodic memory. Trends Cogn Sci 1998;2:399-406.

Nyberg L, McIntosh AR, Houle S, et al. Activation of medial temporal structures during episodic memory retrieval. Nature 1996;380:7157.

Nyberg L, Persson J, Habib R, et al. Large scale neurocognitive networks underlying episodic memory. J Cogn Neurosci 2000;12:16373.

Petersen RC, Smith GE, Ivrik RJ, et al. Memory function in very early Alzheimer's disease. Neurology 1994;44:867-72.

Petrides M, Alivisatos B, Evans AC. Functional activation of the human ventrolateral frontal cortex during mnemonic retrieval of verbal information. Proc Natl Acad Sci USA 1995;92:5803-7.

Pillon B, Deweer B, Agid Y, et al. Explicit memory in Alzheimer's, Huntington's and Parkinson's disease. Arch Neurol 1993;50:374-9.

Reed JM, Squire LR. Impaired recognition memory in patients with lesions limited to the hippocampal formation. Behav Neurosci 1997; 111:667-75.

Ricci PT, Zelkowicz BJ, Nebes RD, et al. Functional neuroanatomy of semantic memory: recognition of semantic associations. Neuroimage 1999;9:88-96.

Schacter DL, Alpert NM, Savage CR, et al. Conscious recollection and the human hippocampal formation: evidence from positron emission tomography. Proc Natl Acad Sci USA 1996;93:321-5.

Signorini M, Paulesu E, Friston K, et al. Rapid assessment of regional cerebral metabolic abnormalities in single subjects with quantitative and nonquantitative (18F)FDG PET: a clinical validation of statistical parametric mapping. Neuroimage 1999;9:63-80.

Small BJ, Herlitz A, Fratiglioni L, et al. Cognitive predictors of incident Alzheimer's disease: a prospective longitudinal study. Neuropsychology 1997;11:413-20.

Squire LR. Memory and the hippocampus: a synthesis from findings with rats, monkeys, and humans. Psychol Rev 1992;99:195-231.

Squire LR, Ojemann JG, Miezin FM, et al. Activation of the hippocampus in normal humans: a functional anatomic study of memory. Proc Natl Acad Sci USA 1992;89:1837-41.

Stern CE, Corkin S, Gonzalez RG, et al. The hippocampal formation participates in novel picture encoding: evidence from functional magnetic resonance imaging. Proc Natl Acad Sci USA 1996;93: 8660-5.

Talairach J, Tournoux P. Co-Planar Stereotaxic Atlas of the Human Brain: 3-Dimensional Proportional System. An Approach to Cerebral Imaging. Stuttgart: Thieme, 1988.

Tounsi H, Deweer B, Ergis AM, et al. Sensitivity to semantic cueing: an index of episodic memory dysfunction in early Alzheimer disease. Alzheimer Dis Assoc Disord 1999;13:38-46.

Tröster AI, Jacobs D, Butters N, et al. Differentiation of Alzheimer's disease from Huntington's disease with the Wechsler Memory ScaleRevised. Clin Geriatr Med 1989;5:611-32.

Tulving E, Thomson DM. Encoding specificity and retrieval processes in episodic memory. Psychol Rev 1973;80:352-72.

Tulving E, Markowitsch HJ. Episodic and declarative memory: role of the hippocampus. Hippocampus 1998;8:198-204.

Tulving E, Kapur S, Markowitsch HJ, et al. Neuroanatomic correlates of retrieval in episodic memory: auditory sentence recognition. Proc Natl Acad Sci USA 1994;91:2012-5.

Tuokko H, Vernon-Wilkinson R, Weir J, et al. Cued recall and early identification of dementia. J Clin Exp Neuropsychol 1991;13:871-9.

Vandenberghe R, Price CJ, Wise R, et al. A common semantic system for words and pictures: functional anatomy. Nature 1996;383:254-6.

Van der Linden M, Coyette F, Wyns C, et al. L'évaluation des troubles de la mémoire verbale: élaboration et étalonnage de quatre épreuves. In: Van der Linden M, Deweer B, Coyette F, et al., eds. Marseille: Solal. In press.

Van Hoesen GW, Hyman BT, Damasio AR. Entorhinal cortex pathology in Alzheimer's disease. Hippocampus 1991;1:1-8. 
Vargha-Khadem F, Gadian DG, Watkins KE, et al. Differential effects of early hippocampal pathology on episodic and semantic memory. Science 1997,277:376-80.

Welsh K, Butters N, Hughes J, et al. Detection of abnormal memory decline in mild cases of Alzheimer's disease using CERAD neuropsychologic measures. Arch Neurol 1991;48:278-81.

Wheeler MA, Stuss DT, Tulving E. Frontal lobe damage produces episodic memory impairment. J Int Neuropsychol Soc 1995;1:52536.
Wiggs CL, Weisberg J, Martin A. Neural correlates of semantic and episodic memory retrieval. Neuropsychologia 1999;37:103-18.

Wilson RS, Fox JH, Kramer RL, et al. Word frequency effect and recognition memory in dementia of the Alzheimer type. J Clin Neuropsychol 1983;5:97-104.

Yonelinas AP, Hopfinger JB, Buonocore MH, et al. Hippocampal, parahippocampal and occipito-temporal contributions to associative and item recognition memory: an fMRI study. Neuroreport 2001; 12:359-63. 